\title{
INFLUENCE OF THE SPACE CHARGE OF AN ION BEAM ON THE TIME-OF-FLIGHT DIAGNOSTICS OF ITS COMPOSITION*
}

\author{
$\underline{\text { A. PUSHKAREV }}{ }^{1,2}$, X.P. ZHU ${ }^{2}$, A. PRIMA ${ }^{1}$, YU.EGOROVA ${ }^{1}$, C.C. ZHANG ${ }^{2}$, M.K. LEI ${ }^{2}$ \\ ${ }^{1}$ Tomsk Polytechnic University, 30, Lenin Ave, Tomsk, 634050, Russia, e-mail: aipush@mail.ru \\ ${ }^{2}$ Dalian University of Technology, Dalian 116024, China, e-mail: surfeng@dlut.edu.cn
}

The results of the time-of-flight diagnostics of the composition of high-intensity pulsed ion beams containing protons and heavy ions are presented. The experiments were performed on two types of ion diodes: an ion diode of focusing (see Fig. 1) and planar geometry in the mode of self-magnetic insulation of electrons $\left(250-300 \mathrm{kV}, 120 \mathrm{~ns}, 20-300 \mathrm{~A} / \mathrm{cm}^{2}\right)$ and a focusing diode with external magnetic insulation $(300 \mathrm{kV}, 80 \mathrm{~ns}$, $100-200 \mathrm{~A} / \mathrm{cm}^{2}$ ). We used a collimated Faraday cup with magnetic cut-off co-moving electrons as a recording device for ions, time resolution of which is one ns [1].

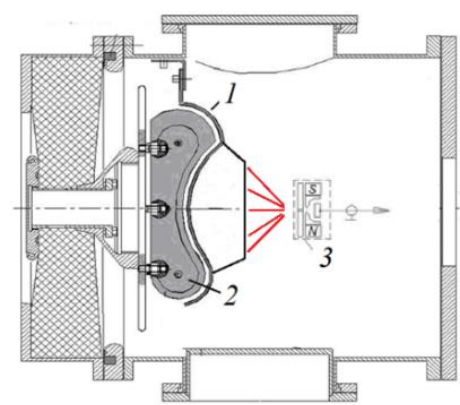

Fig. 1. Schematic of a diode chamber with a focusing diode (1 - cathode; 2 - anode; 3 - Faraday cup)

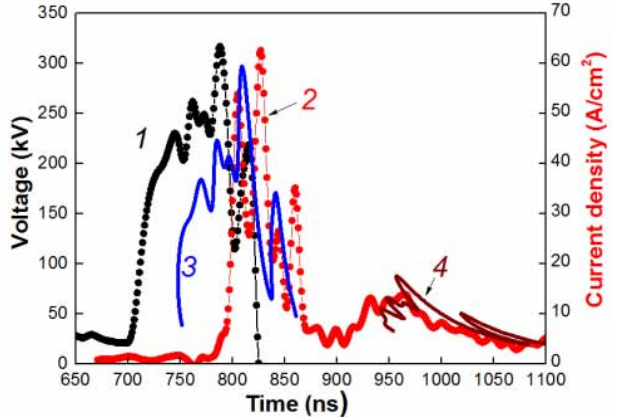

Fig. 2. Waveforms of accelerating voltage, second pulse (1); ion current density in the focus (2, points). Calculated current density of protons (3) and ions $\mathrm{Cu}^{+}(4)$

The time-of-flight diagnostics of pulsed ion beams, containing light ions (protons or deuterons [2]) and heavy ions $\left(\mathrm{C}^{+}\right.$or $\left.\mathrm{Cu}^{+}, \mathrm{N}^{+}\right)$showed a time delay in the experimental data of the light ions registration by the Faraday cup compared with the calculated values [1]. For an ion beam formed by a diode with planar and focusing geometry in the mode of self-magnetic insulation of electrons, the delay was 40-50 ns on the drift path of 14-16 $\mathrm{cm}$ with the ion energy of $250-300 \mathrm{keV}$. For an ion beam formed by a focusing diode in the mode of external magnetic insulation of electrons, the delay was 10-15 ns (on the drift path of $14 \mathrm{~cm}$ at the ion energy of $300 \mathrm{keV}$ ) and $16 \mathrm{~ns}$ (at the ion energy of $1 \mathrm{MeV}$ on the drift path of $45 \mathrm{~cm}$ ) [2]. Heavy ions are recorded by collimated Faraday cup before that predicted by calculation (see Fig. 2). With a low proton concentration, the delay in registration of heavy ions does not exceed the measurement error of the time-offlight diagnostic.

It was shown that the delay of protons registration can be attributed to deceleration of light ions by a negative ion beam space charge during the transport from the diode to the collimated Faraday cup. In the studied ion diodes, the pulse duration of the accelerating voltage does not exceed $120 \mathrm{~ns}$, and in ion beam drift path $(10-16 \mathrm{~cm})$ the total spatial separation of protons and heavy ions due to the difference in ion drift velocity occurred. The neutralization of the positive ions space charge by low-energy electrons is necessary condition for its efficient transport and focusing. Our studies have shown that low-energy electrons do not compensate the positive charge of the protons in the front of beam. However low-energy electrons compensate the positive charge of heavy ions; the concentration of the electrons is 1.3-1.5 times higher than that of ions, the total charge is negative. In the absence of an excess concentration of electrons in the ion beam, the delay in the registration of protons is absent. The effect of spatial compression of the ion beam in the direction of the drift increases its pulse power, but complicates the time-of-flight diagnostics of its composition.

\section{REFERENCES}

[1] A.I. Pushkarev, Y.I. Isakova, A.I. Prima. Laser and Particle beams, 2018, Vol. 36 (2), pp. 210-218.

[2] T.J. Renk, M. Schall, G.W. Cooper. SANDIA REPORT SAND2009-8165, 2009

\footnotetext{
* This work was supported by National Science Foundation of China under Grants Nos. 51371043, 51621064 and Russian Foundation for Basic Research, project no. 17-08-00067.
} 